\title{
EDUCACCÃO AMBIENTAL NO ENSINO MÉDIO DO MUNICÍPIO DE GARANHUNS (PE): SABERES E PRÁTICAS DOCENTES
}

Ana Cristina da Silva Ferreira ${ }^{1}$

Marcelo Simões Tessmann²

Cristiane Tessmann ${ }^{3}$

Resumo: A relação entre meio ambiente e educação assume um papel cada vez mais desafiado. O objetivo deste trabalho foi conhecer as ações de Educação Ambiental desenvolvidas pelos professores do Ensino Médio de Garanhuns (PE). Foi realizado aplicação de questionários para coletar os dados da pesquisa. Os resultados mostraram que os professores possuem sólidos conhecimentos acerca da temática ambiental. Também pode-se observar que a maioria das escolas não tem um projeto de Educação Ambiental, trabalhando a temática de forma isolada em algumas disciplinas e utilizando como prática didática, principalmente, a leitura e interpretação de textos. A principal dificuldade em desenvolver projetos interdisciplinares foi o reduzido tempo de convívio entre os professores.

Palavras-chave: Dificuldades; Educação Ambiental; Práticas; Projetos.

2 IFPE Campus Garanhuns. E-mail: marcelo.tessmann@garanhuns.ifpe.edu.br.

3 IFBA Campus Porto Seguro. E-mail: cristianetessmann@ifba.edu.br. 


\section{Introdução}

O homem está constantemente agindo sobre o meio a fim de satisfazer suas necessidades e desejos. Cada indivíduo percebe, reage e responde diferentemente frente às ações sobre 0 meio. As rápidas modificações ambientais, decorrentes do avanço desenfreado das diferentes atividades humanas, constituem uma ameaça constante à biodiversidade e podem estar relacionadas ao nível de compreensão e percepção da sociedade no que diz respeito à problemática ambiental (BEZERRA; GONÇALVES, 2007). A necessidade de superação dos impasses de ordem ambiental fez da Educação Ambiental (EA) uma exigência primordial, na tentativa de promover as necessárias transformações de comportamento e pensamento (PEREIRA et al., 2010).

A EA surgiu no Brasil e no mundo Ocidental de modo geral a partir da constatação de que a educação deveria ser capaz de reorientar as premissas do agir humano em sua relação com o meio ambiente (GRUN, 2003). Sendo uma dimensão da educação, a EA é um processo educativo que visa formar cidadãos éticos nas suas relações com a sociedade e com a natureza. Durante a formação, cada indivíduo é levado a uma reflexão de seus comportamentos e valores pela aquisição de conhecimentos, compromisso e responsabilidade com a natureza e com as gerações futuras. A EA contribui para que o indivíduo seja parte atuante na sociedade, aprendendo a agir individual e coletivamente na busca de soluções (REIGADA; REIS, 2004).

A EA traz consigo uma nova pedagogia que surge da necessidade de orientar a educação dentro do contexto social e na realidade ecológica e cultural onde se situam os sujeitos e atores do processo educativo (LEFF, 2009).

Por não se tratar de uma disciplina, a EA permite inovações metodológicas na direção do educere - tirar de dentro - por ser necessariamente motivada pela paixão, pela delícia do conhecimento e da prática voltados para a dimensão complexa da manutenção da vida. A EA, por não estar presa a uma grade curricular rígida, pode ampliar conhecimentos em uma diversidade de dimensões, sempre com foco na sustentabilidade ambiental local e do planeta, aprendendo com as culturas tradicionais, estudando a dimensão da ciência, abrindo janelas para a participação em políticas públicas de meio ambiente e para a produção do conhecimento no âmbito da escola. Com essa visão sistêmica e participativa, espera-se que esses processos educacionais permitam incentivar educadores e educadoras ambientais a acreditarem em sua capacidade de atuação individual e coletiva, ao se apropriarem de conceitos, readequando métodos, incrementando técnicas e melhorando suas práticas cotidianas (SORRENTINO et al., 2005).

A relação entre meio ambiente e educação assume um papel cada vez mais desafiador demandando a emergência de novos saberes para apreender processos sociais complexos e riscos ambientais que se intensificam (JACOBI, 2004).

revista brasileira educação ambiental 
A partir dos Parâmetros Curriculares Nacionais (PCNs), o tema ambiente foi incluído como tema transversal no currículo da escola fundamental, o que garante, definitivamente, 0 tratamento interdisciplinar característico dessa temática. O envolvimento dos professores dos diferentes componentes curriculares na elaboração de propostas de ensino relacionadas com a temática ambiental, a partir de seu campo de trabalho, pode garantir que os projetos desenvolvidos pela escola, ou por um grupo de professores, não sejam vistos como atividades extracurriculares (CARVALHO, 2001). Assim, o tratamento da EA como tema transversal no currículo da Escola leva ao aprofundamento das fontes teóricas que fundamentam sua teoria e sua prática pedagógica (MEDINA, 2002).

Assim, o educador tem a função de mediador na construção de referenciais ambientais e deve saber usá-los como instrumentos para o desenvolvimento de uma prática social centrada no conceito da natureza (JACOBI, 2004). Essa nova realidade, que exige uma reflexão centrada na inter-relação entre saberes e práticas coletivas, lança desafios relacionados à formação/capacitação dos docentes para o processo de incorporação da dimensão ambiental nos currículos do Ensino Fundamental e Médio, impulsionando a reflexão sobre as características docentes e discentes, responsáveis pela efetiva implementação do processo, e sobre a instituição o escola onde deverão ser produzidas as mudanças que envolvem as atividades dos agentes sociais mencionados (MEDINA, 2002).

A EA se constitui tão complexa e dinâmica que exige um processo educativo fundamentado na ação-reflexão-ação para revelar-se plena de significados concretos das realidades social e ambiental. Assim, uma das possibilidades para a EA crítica e transformadora na educação escolar é a formação plena dos professores da educação básica (REIS et al., 2012). Por isso, os Ministérios da Educação e Cultura (MEC) e o do Meio Ambiente (MMA), em consonância com a Política Nacional de Educação Ambiental (PNEA) e o Programa Nacional de Educação Ambiental (ProNEA), desenvolvem propostas de formação de educadores(as) ambientais. Ambos atuam junto aos seus públicos específicos dentro de uma perspectiva crítica, popular e emancipatória e almejam desvelar processos continuados articulados com processos transformadores a partir de uma visão sistêmica e permanente do processo educacional, em detrimento de cursos pontuais ou de um ativismo vazio (SORRENTINO et al., 2005).

Apesar disso, a discussão da problemática ambiental situa-se dentro de uma visão simplista e superficial, onde os aspectos físicos e biológicos são enfatizados em detrimento dos aspectos social, político, cultural, ético e econômico. As atividades de EA estão sendo desenvolvidas de maneira isolada do currículo escolar, conduzidas como atividades extracurriculares, não havendo a devida ligação entre os saberes sistematizados pela escola e outros saberes. Esse fato dificulta aos educandos e educadores o desenvolvimento de uma leitura crítica e complexa da questão ambiental (MACHADO, 2008). Além disso, a falta de engajamento dos professores em projetos de EA tem sido

Revbea, São Paulo, V. 11, № 4: 210-225, 2016. 
apontada como um dos fatores responsáveis pelas dificuldades de implementação destes em escolas públicas, com implicação na incidência de abordagens superficiais e descontínuas do tema meio ambiente (LIMA, 2012).

Como os diferentes autores que têm trabalhado com a formação de professores e com a implementação de currículos têm alertado, no caso da incorporação da temática ambiental pela escola, o envolvimento do professor é o primeiro passo a ser dado. O professor, além de sensibilizado e consciente da necessidade e da importância do tratamento dessa questão com seus alunos, deve estar preparado e instrumentalizado para enfrentar esse desafio (CARVALHO, 2001).

O educador ambiental necessita aprender e valorizar o trabalho que está pretendendo realizar, devendo especializar-se através de leituras na área, participando de encontros, adquirindo um conhecimento sólido para trabalhar de modo pertinente os conteúdos da área e com metodologias adequadas para o desenvolvimento do conhecimento e de atitudes críticas sobre a realidade socioambiental (SANTOS; PARDO, 2011). Nesse sentido, os cursos de formação inicial dos professores desenvolvidos nas universidades poderiam investir em uma estrutura curricular muito mais flexível e dinâmica que facilitasse o tratamento das questões ambientais nos diferentes cursos de licenciatura por meio de experiências diversificadas e de uma abordagem que envolvesse os vários aspectos desse tema. A criação de disciplinas com o intuito de responder a essa demanda apresenta sempre os limites impostos ao trabalho disciplinar, embora não seja, necessariamente, uma experiência negativa (CARVALHO, 2001).

A interdisciplinaridade constitui um dos conceitos mais importantes do pensamento educacional contemporâneo. Essa ideia, geradora de teorias e práticas, tem inspirado importantes transformações no contexto escolar, denunciando a fragmentação do currículo e a necessidade de transformar a natureza dos processos de aprendizagem (GARCIA, 2012). A prática da interdisciplinaridade é uma maneira de articular pessoas e conhecimentos, com vistas à percepção do ser humano na sua integralidade. $\mathrm{O}$ ponto fundamental do trabalho interdisciplinar, de concepção teórica ou prática é a troca de conhecimentos que se estabelece no interior das interações, enriquecendo os conhecimentos, ampliando os campos de visão dos profissionais envolvidos (GATTÁS; FUREGATO, 2007). O professor que se precisa é aquele que conhece bem sua matéria, que tem uma boa compreensão entre as várias disciplinas e que conheça como os alunos constroem seus conhecimentos, desenvolvem suas capacidades mentais e na prática saber estimular esse processo de ensino-aprendizagem. Sendo assim encarar uma mudança na educação, como a interdisciplinaridade, propõe uma atitude permanente de crítica e reflexão, de compromisso e responsabilidade com a tarefa de educar (FORTES, 2012).

Sendo assim, o objetivo deste trabalho foi realizar um levantamento de informações acerca dos saberes docentes do Ensino Médio do município de 
Garanhuns/PE em relação à Educação Ambiental, bem como suas práticas com essa temática.

\section{Metodologia}

\section{Caracterização da área de estudo}

Garanhuns é uma cidade localizada no Agreste Meridional do estado de Pernambuco, que possui uma população de 129.408 habitantes, distribuída em uma área com $459 \mathrm{~km}^{2}$ (IBGE, 2010). A cidade possui 351 docentes, distribuídos nas redes municipal, estadual, federal e privada de ensino.

$\mathrm{Na}$ cidade existem cinco escolas privadas e treze escolas estaduais que possuem Ensino Médio. No entanto, inicialmente foi realizado o trabalho em apenas quatro das escolas privadas e oito das escolas públicas. Os professores do Ensino Médio destas escolas é que foram o objeto de estudo deste trabalho, constando um total de 88 docentes.

\section{Coleta e análise de dados}

Para coleta dos dados, realizada nos anos de 2012 e 2013, foi aplicado um questionário dividido em duas partes, sendo a primeira relacionada a dados pessoais e a segunda relacionada ao levantamento do conhecimento e atividades práticas com a temática ambiental. $\mathrm{Na}$ elaboração do questionário foi fundamental o levantamento preliminar de informações que permitiram a elaboração das perguntas, direcionadas a fazer emergir elementos relativos às práticas da temática ambiental em suas atividades. Os questionários foram aplicados diretamente aos professores por sua coordenação, nos seus respectivos turnos de trabalho.

As informações foram analisadas com base na frequência de respostas dos indivíduos.

\section{Resultados e Discussão}

Das escolas participantes da pesquisa, apenas cinco possuem projeto de $E A$. As demais possuem ações isoladas à $E A$, normalmente restrita às disciplinas de biologia e geografia. Os trabalhos envolvendo EA nas escolas são, em sua maioria, esporádicos, sem continuidade e muito simples (BIZERRIL; FARIA, 2001). Projetos como fonte de organização do trabalho pedagógico pode constituir-se em uma rica oportunidade para valorizar e promover a autonomia do professor, bem como para favorecer a colaboração e a integração entre pessoas, conhecimentos, disciplinas e metodologias (SANTOS; JACOBI, 2011).

As informações relativas ao perfil geral dos entrevistados encontram-se demonstrado na Tabela 1. A formação dos docentes participantes se encontra coerente com os níveis e modalidades de ensino em que os professores estão inseridos. No entanto, apenas $42 \%$ dos docentes das escolas privadas e $23,7 \%$ 
dos docentes das escolas públicas que participaram da pesquisa já realizaram algum curso de capacitação na área ambiental. A necessidade permanente de formação continuada desses docentes em outros tipos de ações promotoras de sua qualificação, como a participação em eventos, cursos de curta duração, formação em serviço, etc., não pode deixar de ser incentivada (SILVA, 2012).

Tabela 1: Perfil dos docentes do Ensino Médio das escolas públicas e privadas de Garanhuns (PE).

\begin{tabular}{|c|c|c|c|c|c|c|c|c|c|c|c|c|c|}
\hline \multirow{2}{*}{\multicolumn{2}{|c|}{ CARACTERÍSTICAS }} & \multicolumn{4}{|c|}{ ESCOLAS PRIVADAS } & \multicolumn{8}{|c|}{ ESCOLAS PÚBLICAS } \\
\hline & & 1 & 2 & 3 & 4 & 1 & 2 & 3 & 4 & 5 & 6 & 7 & 8 \\
\hline SEXO & $\begin{array}{l}\mathrm{M} \\
\mathrm{F}\end{array}$ & $\begin{array}{l}60 \% \\
40 \%\end{array}$ & $\begin{array}{l}60 \% \\
40 \%\end{array}$ & $\begin{array}{l}50 \% \\
50 \%\end{array}$ & $\begin{array}{l}83,3 \% \\
16,7 \%\end{array}$ & $\begin{array}{l}33,3 \% \\
66.7 \%\end{array}$ & $\begin{array}{l}25 \% \\
75 \%\end{array}$ & $\begin{array}{l}55,6 \% \\
44,4 \%\end{array}$ & $\begin{array}{l}62,5 \% \\
37,5 \%\end{array}$ & $\begin{array}{c}0 \% \\
100 \%\end{array}$ & $\begin{array}{l}30 \% \\
70 \%\end{array}$ & $\begin{array}{c}0 \% \\
100 \%\end{array}$ & $\begin{array}{l}23,5 \% \\
76,5 \%\end{array}$ \\
\hline \multirow{4}{*}{ IDADE } & $\begin{array}{c}< \\
25\end{array}$ & $0 \%$ & $10 \%$ & $0 \%$ & $0 \%$ & $33,3 \%$ & $0 \%$ & $0 \%$ & $12,5 \%$ & $0 \%$ & $0 \%$ & $0 \%$ & $0 \%$ \\
\hline & 25- & $40 \%$ & $60 \%$ & $50 \%$ & $50 \%$ & $0 \%$ & $12,5 \%$ & $77,8 \%$ & $75 \%$ & $50 \%$ & $50 \%$ & $0 \%$ & $47,1 \%$ \\
\hline & $\begin{array}{l}36- \\
45\end{array}$ & $40 \%$ & $10 \%$ & $37,5 \%$ & $0 \%$ & $33,3 \%$ & $62,5 \%$ & $22,2 \%$ & $12,5 \%$ & $50 \%$ & $10 \%$ & $0 \%$ & $35,3 \%$ \\
\hline & $>45$ & $0 \%$ & $0 \%$ & $12.5 \%$ & $50 \%$ & $33,3 \%$ & $25 \%$ & $0 \%$ & $0 \%$ & $0 \%$ & $30 \%$ & $100 \%$ & $17,7 \%$ \\
\hline \multirow{5}{*}{$\begin{array}{c}\text { GRAU DE } \\
\text { INSTRUÇÃO }\end{array}$} & $\mathrm{Gl}$ & $0 \%$ & $0 \%$ & $0 \%$ & $0 \%$ & $0 \%$ & $0 \%$ & $0 \%$ & $12,5 \%$ & $0 \%$ & $0 \%$ & $0 \%$ & $0 \%$ \\
\hline & G & $0 \%$ & $0 \%$ & $0 \%$ & $0 \%$ & $33,3 \%$ & $25 \%$ & $11,1 \%$ & $25 \%$ & $0 \%$ & $0 \%$ & $100 \%$ & $0 \%$ \\
\hline & $\mathrm{E}$ & $60 \%$ & $70 \%$ & $62,5 \%$ & $66,7 \%$ & $0 \%$ & $75 \%$ & $77,8 \%$ & $62,5 \%$ & $100 \%$ & $80 \%$ & $0 \%$ & $64,7 \%$ \\
\hline & $\mathrm{Me}$ & $40 \%$ & $30 \%$ & $25 \%$ & $16,7 \%$ & $66,7 \%$ & $0 \%$ & $11,1 \%$ & $0 \%$ & $0 \%$ & $0 \%$ & $0 \%$ & $17,7 \%$ \\
\hline & $\mathrm{D}$ & $0 \%$ & $0 \%$ & $0 \%$ & $0 \%$ & $0 \%$ & $0 \%$ & $0 \%$ & $0 \%$ & $0 \%$ & $10 \%$ & $0 \%$ & $0 \%$ \\
\hline
\end{tabular}

$\mathrm{M}=$ masculino; $\mathrm{F}=$ feminino

$\mathrm{Gl}$ = graduação incompleta; $\mathrm{G}$ = graduação; $\mathrm{E}$ = especialização; $\mathrm{Me}=$ mestrado; $\mathrm{D}$ = doutorado

Fonte: Autoria própria.

No trabalho de EA é de extrema importância o conhecimento prévio das concepções ambientais dos sujeitos envolvidos, a fim de guiar as ações educativas de maneira a produzir um conhecimento significativo; uma concepção ambiental equivocada pode resultar em ações limitadas ou ineficientes (ESTEVAM; GAIA, 2014). Assim, quando questionados sobre palavras que indicam meio ambiente, as mais citadas pelos professores das escolas privadas foram sustentabilidade $(60 \%)$, seguida por preservação $(20 \%)$ e consciência e ecologia (20\%). Já entre os professores das escolas públicas predominaram vida $(17 \%)$, preservação $(11,1 \%)$ e sustentabilidade $(9,6 \%)$. Segundo Carneiro (2002), estas respostas colocam-se mais como objetivos da EA do que um entendimento conceitual de meio ambiente. $O$ termo sustentabilidade focaliza a necessidade de se cuidar do ambiente em vista da qualidade de vida e preservação e consciência e ecologia corresponde à orientação naturalista (vertente ecológico-preservacionista), disseminada pelos meios de comunicação e refletida na cultura escolar. No entanto, o resultado encontrado demonstra estarmos diante de professores que possuem consciência ambiental, muito mais do que conceitos biológicos/ecológicos de meio ambiente, apresentando uma visão contextualizada da realidade ambiental, com ênfase na incorporação efetiva dos aspectos sócio-econômicoculturais (BEZERRA; GONÇALVES, 2007).

Segundo os docentes, as atividades humanas que mais contribuem para degradação ambiental são sociedade em geral $(43,2 \%)$, indústria $(38,6 \%)$ e mineração (5,7\%). Em trabalho realizado por Slonski (2011) foi encontrado 
resultado semelhante, porém, a indústria foi citada mais vezes e ao invés de mineração, foi citada a pecuária como o terceiro segmento responsável pela degradação ambiental.

Em outra questão foi solicitado aos professores que classificassem alguns problemas ambientais quanto à sua gravidade em: muito grave, grave ou pouco grave. Conforme se observa na Figura 1, os problemas ambientais considerados muito graves mais citados foram extinção das espécies $(88,6 \%)$, aquecimento global, desmatamento e redução da camada de ozônio $(87,5 \%)$ e poluição do ar (84,1\%). Estes resultados diferem do que foi encontrado por Slonski (2011), cujos problemas citados foram poluição da água $(90 \%)$, desmatamento (81\%), extinção de espécies $(81 \%)$ e lixo $(81 \%)$. Com relação aos problemas ambientais considerados pouco graves, os resultados dos dois trabalhos foram semelhantes (poluição sonora e espécies transgênicas).

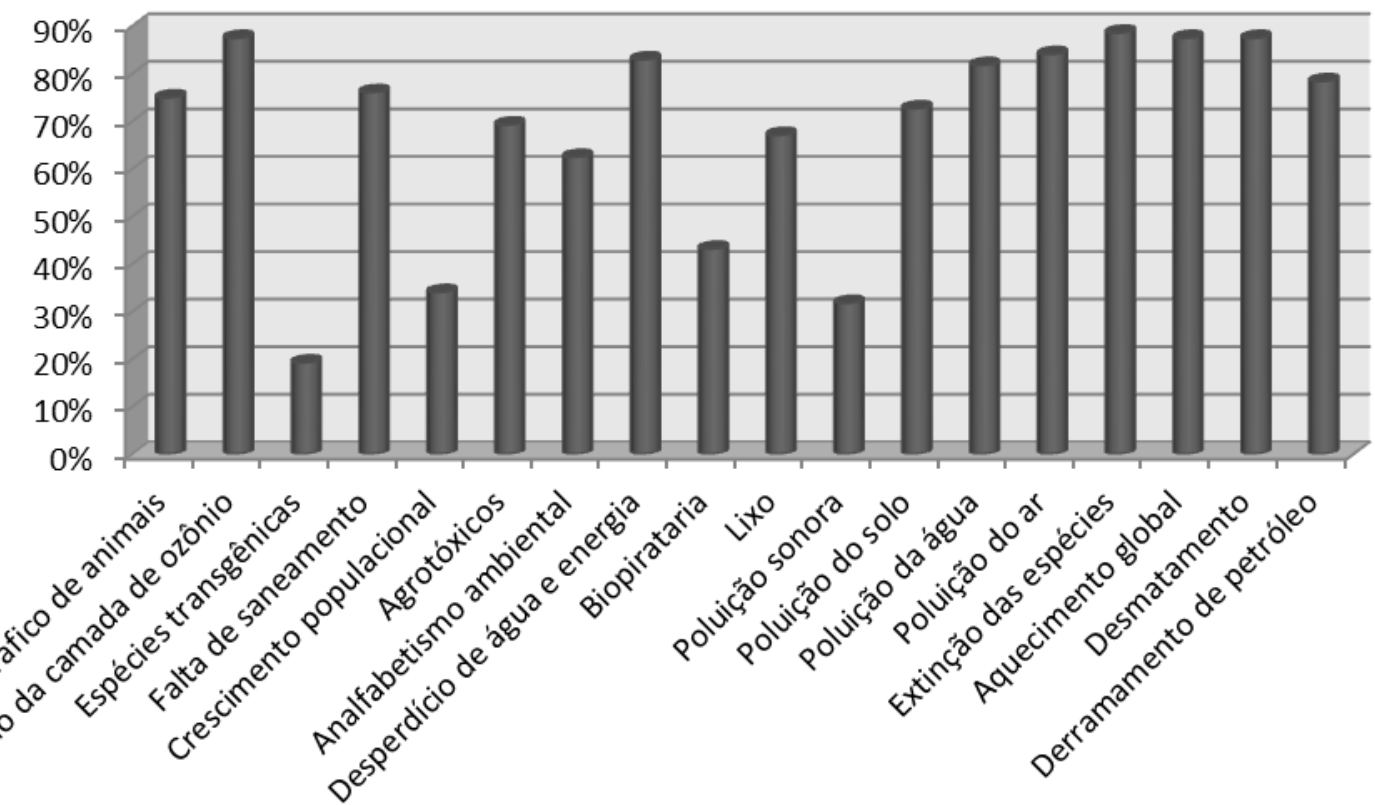

Figura 1: Problemas considerados muito graves pelos docentes do Ensino Médio das escolas de Garanhuns (PE). Fonte: Autoria própria.

Com o objetivo de verificar a capacidade dos professores de analisar o ambiente a sua volta e de detectar os principais problemas ambientais locais, foi solicitado que eles listassem os três principais problemas do município de Garanhuns. Problemas de saneamento tiveram destaque com $29,9 \%$ das respostas, seguido do lixo $(22,1 \%)$ e poluição das águas $(12,1 \%)$, como demonstra a Figura 2. Esse fato reflete a falta de tratamento do esgoto na maioria dos bairros da cidade, causando mau cheiro e proliferação de insetos em várias locais do município. Apesar do lixo ter sido citado como o segundo maior problema ambiental municipal, Garanhuns possui coleta de lixo regular e aterro sanitário, estando incluído atualmente no Programa Recicla Pernambuco, que visa promover a coleta seletiva. Além disso, Garanhuns é um Revbea, São Paulo, V. 11, № 4: 210-225, 2016. 
município onde se encontram vários mananciais, os quais apresentam problemas muito sérios relacionados à poluição, fato este que pode justificar a citação da poluição das águas pelos docentes pesquisados. Merece atenção o fato de que o problema contaminação do solo ter aparecido em apenas $1,3 \%$ das respostas, pois uma das principais atividades econômicas do município é a agricultura e a utilização de herbicidas, fungicidas e agrotóxicos ocorre com frequência, visto que a produção orgânica ainda é baixa no município.

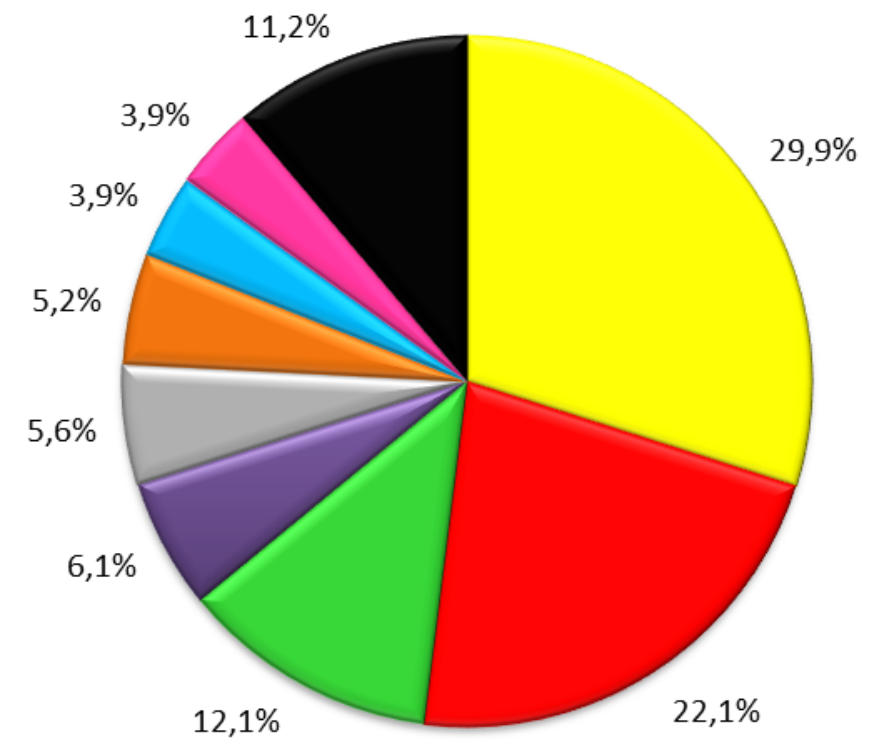

$$
\begin{aligned}
& \square \text { saneamento } \\
& \square \text { lixo } \\
& \square \text { poluição das águas } \\
& \square \text { desmatamento } \\
& \square \text { analfabetismo ambiental } \\
& \square \text { desperdídio de água } \\
& \square \text { voçoroca } \\
& \square \text { crescimento desordenado } \\
& \square \text { outros }
\end{aligned}
$$

Figura 2: Principais problemas ambientais segundo os docentes do Ensino Médio das escolas de Garanhuns (PE). Fonte: Autoria própria.

Em uma das questões foi solicitado aos participantes que avaliassem seu envolvimento em ações ambientais feitas faz regularmente. A maioria dos docentes participantes desta pesquisa respondeu que utiliza a temática ambiental nas aulas $(59,1 \%)$, reduz o consumo de água $(55,7 \%)$ e de papel $(46,6 \%)$, participa de projetos ambientais na escola $(43,2 \%)$, evita produtos descartáveis e separa o lixo para reciclagem (37,5\%) (Figura 3). Apenas 25\% dos participantes da pesquisa afirmaram que reduzem o uso do automóvel para minimizar a emissão de monóxido de carbono e, consequentemente, minimizando o efeito estufa. Outros dados que chamaram atenção foi o fato de que a maioria dos docentes não utiliza sacolas retornáveis. Em trabalho realizado por Slonski (2011), a atividade realizada com maior frequência foi o encaminhamento do lixo para a reciclagem $(86 \%)$ seguida do encaminhamento do óleo de cozinha usado (68\%) e da redução do consumo de água (63\%). 


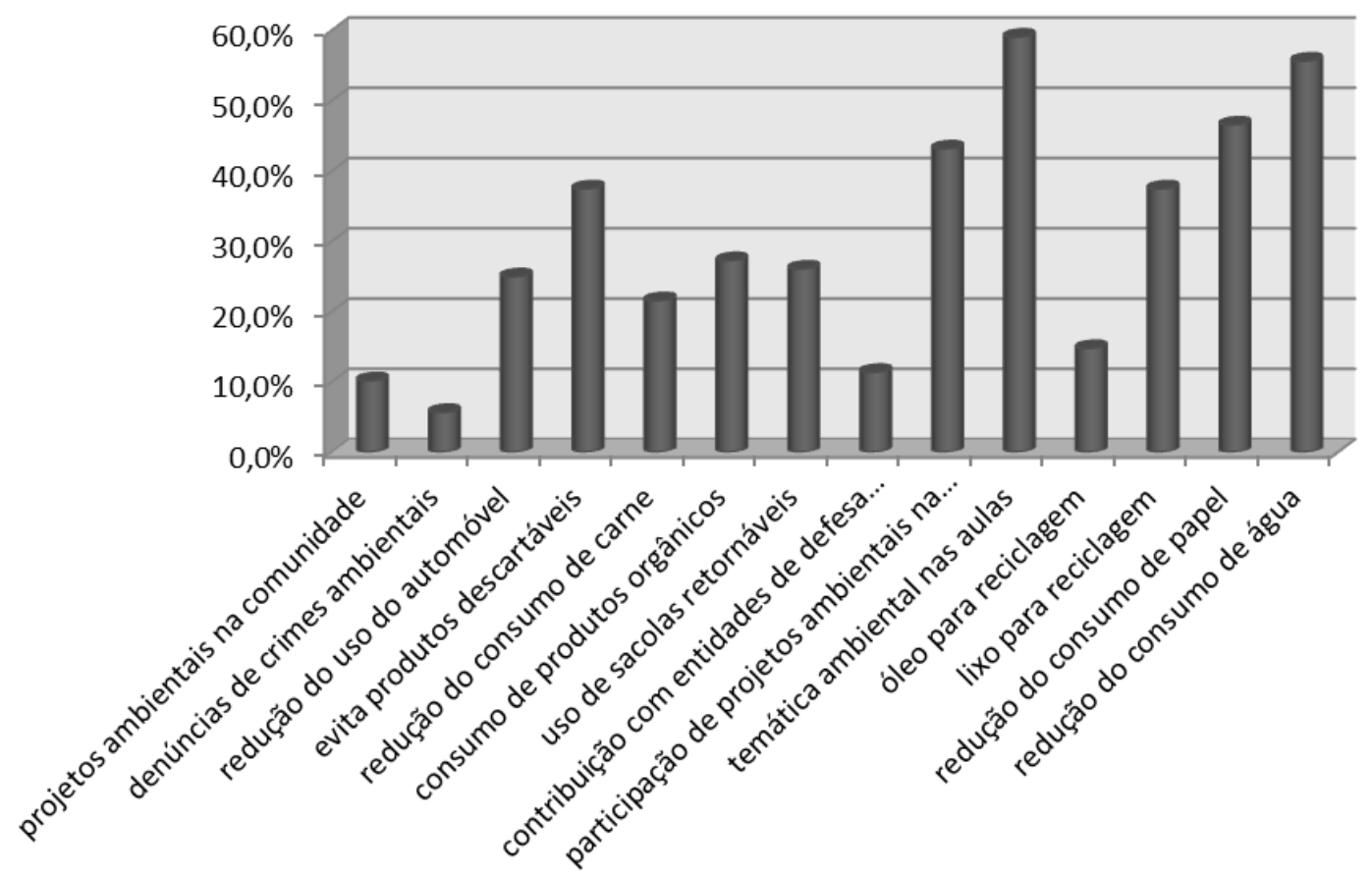

Figura 3: Ações ambientais realizadas regulamente pelos docentes do Ensino Médio das escolas de Garanhuns (PE). Fonte: Autoria própria.

As formas de inserção da EA nas escolas são muito variadas, assim como o são os muitos fatores determinantes dessas propostas educativa, tais como: que tipo de profissional está envolvido com a EA nessas escolas, qual sua formação e atuação, quais os temas mais recorrentes, há quanto tempo as escolas desenvolvem essas práticas, como estruturam essa inserção, que propostas pedagógicas a caracterizam, entre outros (REIS et al., 2012). Ao serem questionados sobre a maneira em que as questões ambientais são abordadas em sala de aula, foi possível constatar conforme Figura 4 as formas que os docentes participantes da pesquisa trabalham a temática ambiental em sua prática educativa. Provavelmente devido a facilidade, a forma mais utilizada para trabalhar as questões ambientais foi a leitura e interpretação de textos. Resultado semelhante foi encontrado no trabalho realizado por Viana \& Oliveira (2006), onde $40 \%$ dos professores entrevistados utilizam textos relacionados à temática ambiental para abordar o tema em sala de aula. Em pesquisa realizada sobre EA em uma escola municipal de Mamanguape/PB, os professores citaram trabalhos em grupo e apresentações orais $(60 \%)$ e filmes, slides, apresentação audiovisual, palestras e seminários (40\%). Já debates, visitas/passeios/excursões, peças teatrais, músicas e jogos foram os métodos menos citados (PEREIRA, 2012). Na Escola Agrotécnica Federal de Vitória de Santo Antão/PE, houve um predomínio de oficinas e palestras $(16,66 \%)$, seguido de leitura e interpretação de texto, pesquisas e debates $(13,88 \%)$ (BEZERRA; GONÇALVES, 2007). Predomínio de estudo dirigido e aulas práticas foram as práticas didáticas apontados no trabalho de Soares e Gurgel Revbea, São Paulo, V. 11, № 4: 210-225, 2016. 
(2012), enquanto que saídas de campo foram apontadas por um número menor de professores, apesar de ser uma prática muito recomendada por educadores ambientais.

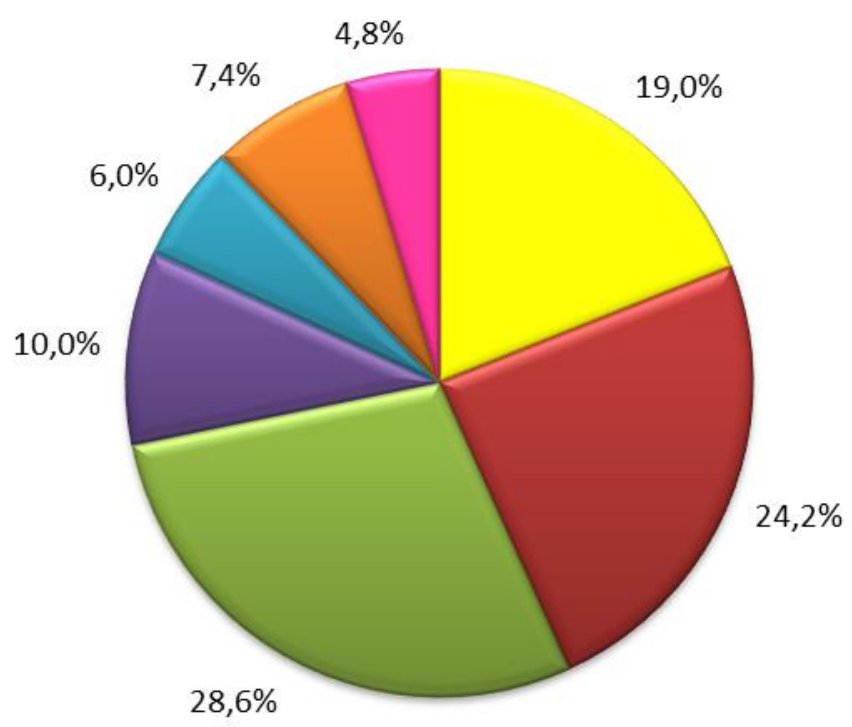

$\square$ palestras e oficinas

pesquisas e debates

$\square$ leitura e interpretação de textos

plantio de mudas de árvores

horta orgânica

$\square$ visita a zoológicos

visita a museus

Figura 4: Formas de abordagem das questões ambientais na sala de aula pelos docentes do Ensino Médio das escolas de Garanhuns/PE. Fonte: Autoria própria.

Todas as ações e práticas citadas na Figura 4 possuem indiscutível relevância; no entanto, devem ser relacionadas aos determinantes sociais e econômicos para poderem auxiliar na adoção de certos comportamentos, assegurando a compreensão da questão ambiental em sua totalidade e materialidade (AMBIVEREO et al., 2015). Trabalhar a EA na forma de projeto interdisciplinar é uma forma eficaz de agir, pois assim evitamos tratá-la de forma excepcional e externa, associada a datas comemorativas e festivas, desarticulada dos conteúdos das áreas de conhecimento e convívio escolar, bem como com a comunidade em que a escola está inserida (NEHME; COLESANTI, 2005). Cabe lembrar que os projetos interdisciplinares são considerados metodologias relevantes para a compreensão da questão ambiental em sua complexidade, embora não ofereçam garantia de transformação social (GUIMARÃES et al., 2012).

Compreende-se que as propostas voltadas para a implantação da EA no ensino formal são necessárias para o desenvolvimento das atividades que visem os princípios da interdisciplinaridade e da transversalidade. Porém, a realidade do cotidiano escolar tem demonstrado o contrário devido às dificuldades encontradas (VIANA; OLIVEIRA, 2006), tais como aquelas citadas pelos professores participantes da pesquisa (Figura 5). 

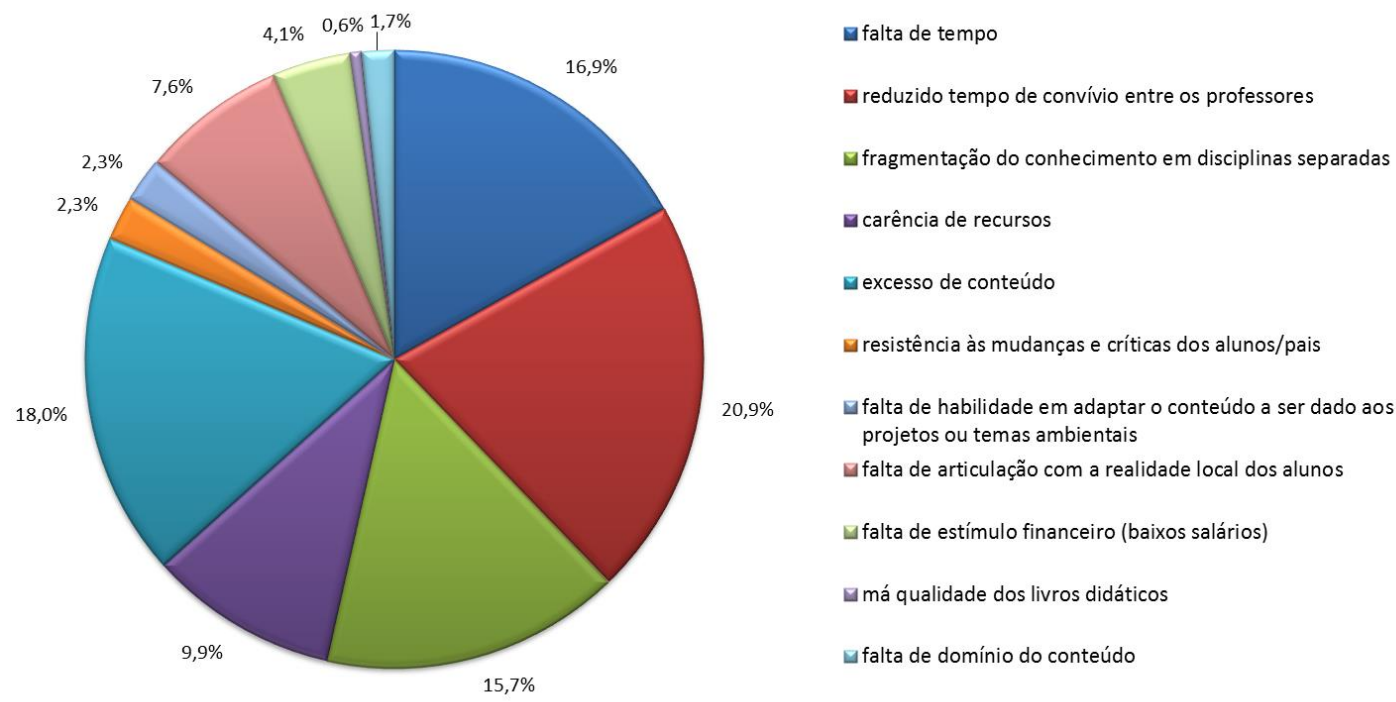

Figura 5: Principais dificuldades para trabalhar a temática ambiental na forma de projetos interdisciplinares segundo os docentes do Ensino Médio de Garanhuns (PE).

Fonte: Autoria própria.

Uma das dificuldades encontradas para trabalhar com a temática ambiental de forma interdisciplinar foi fragmentação do conhecimento em disciplinas separadas $(15,7 \%)$. Para que a transversalidade seja efetivada na prática pedagógica é necessário que sejam eliminadas as barreiras entre as disciplinas (CUBA, 2010).

O fator tempo mostrou-se como um agravante para um melhor desempenho da interdisciplinariedade, principalmente quando o tempo de convivio entre docentes não é suficiente para diálogos.

Em trabalho realizado por Cavalcanti Neto e Amaral (2011), 58,4\% dos professores entrevistados responderam que inserir elementos de EA na sala de aula é uma tarefa difícil. As principais dificuldades citadas foram: mudar hábitos já formados dos alunos, a falta de suporte financeiro e aparelhamento das escolas, falta de capacitação do professor dentro da área, falta de interação entre as disciplinas e resistência dos professores. Um dos principais problemas parece estar relacionado à necessidade de mudanças nas estratégias de ensino para abordagem de problemas ligados aos contextos sócio-ambientais e cotidianos dos alunos. $\mathrm{E}$ isso parece condicioná-los, diminuindo a disponibilidade e abertura a inovações programáticas e didáticas (MARQUES, 2012).

Em pesquisa realizada no Distrito Federal, as principais dificuldades dos professores foram questões orçamentárias e estruturais (BIZERRIL; FARIA, 2001). A dificuldade "carência de recursos" apresentou grande diferença na frequência de citações entre os professores das escolas públicas $(27,1 \%)$ e privadas $(3,5 \%)$, sugerindo que este problema nas escolas públicas 
deve ser considerado como um forte motivo para o não desenvolvimento de projetos interdisciplinares na área ambiental. Resultado semelhante foi encontrado por Soares e Gurgel (2012), no qual 60\% dos professores responderam que a falta de material é um fator limitante para 0 desenvolvimento da temática ambiental. A falta de suporte financeiro e de recursos materiais também foi apontado como uma das maiores dificuldades para desnvolver projetos de EA (GUIMARÃES et al., 2012).

$\mathrm{Na}$ prática educativa ambiental, os professores lançam mão de conhecimentos que, embora buscados em fontes muito variadas, mostram-se fragmentados e superficiais do ponto de vista do necessário domínio dos saberes escolares para a inserção da temática ambiental (REIS et al., 2012). Os problemas "falta de habilidade em adaptar o conteúdo a ser dado aos projetos ou temas ambientais" e "falta de articulação com a realidade local dos alunos" poderiam ser resolvidos através da realização de capacitação, pois o profissional de educação que se capacita possui um leque de possibilidades e será capaz de aplicar práticas pedagógicas não só em sua sala de aula, mas na comunidade escolar e até na comunidade de entorno, conduzindo seus alunos a criticarem alguns aspectos da sua realidade local e também da global (SANTOS; PARDO, 2011).

Nossos resultados contrariam os encontrados por Fernandes et al. (2014), no qual $88 \%$ dos professores entrevistados afirmaram que não há dificuldades em desenvolver trabalho/projetos com a temática ambiental. No entanto, a superação das dificuldades acima citadas, em nível local ou nacional, demanda ações que vão desde a otimização de infraestrutura nas escolas até a valorização profissional dos docentes, o que inclui programas de formação bem estruturados e com objetivos bem definidos (CAVALVANTI NETO; AMARAL, 2011).

É válido salientar que para os docentes ainda é pouco o investimento por parte do sistema educacional em qualificá-los para trabalhar com questões ambientais no ensino formal, o que contribui para uma dificuldade em associar os conteúdos às diversas áreas, levando a continuidade do trabalho de forma desarticulada (VIANA; OLIVEIRA, 2006). Este problema não deveria ocorrer visto que a Política Nacional de Educação Ambiental determina que os professores em atividade devem receber formação complementar em suas áreas de atuação (BRASIL, 1999).

Uma outra questão levantada foi acerca da importância da formação de recursos humanos exclusivamente em EA, assunto este que já faz parte dos temas discutidos no meio cientifico/acadêmico/politico. Segundo Cuba (2010), a EA no âmbito escolar deve ser tratada como científica, ou seja, deve ser uma disciplina que atue separadamente das outras. Entre os professores participantes da pesquisa, 40,2\% defendem a ideia de existir uma disciplina exclusiva de EA a fim de melhorar o aprendizado acerca do assunto. Cabe lembrar que isto está em desacordo com a Política Nacional de Educação Ambiental, que diz que a EA não deve ser implantada como disciplina específica no currículo de ensino (BRASIL, 1999). No entanto, em trabalho

revista brasileira educação ambiental 
realizado por Mendes et. al. (2012) ao seres perguntados se a escola deveria ter um profissional para desenvolver atividades de EA, $71 \%$ dos docentes responderam que sim.

Atualmente, o grande desafio é a criação de políticas públicas que garantam uma formação adequada, a produção de materiais didáticos ajustados às necessidades escolares e uma gestão escolar que permita que a EA seja estruturante das práticas pedagógicas (AMBIVERO et al., 2015).

\section{Conclusões}

A percepção dos docentes do Ensino Médio de Garanhuns (PE) sobre a temática ambiental e suas práticas estão de acordo com educadores, formadores de opinião e que atuam em diversas áreas do conhecimento. No entanto, fica claro que tais professores necessitam capacitar-se para trabalhar de maneira interdisciplinar os temas transversais, mais especificamente o tema meio ambiente.

A dificuldade de desenvolver um trabalho pautado no princípio da interdisciplinaridade se fez presente principalmente devido a falta de convívio entre os professores. A principal maneira de trabalhar a temática ambiental é através de leitura e interpretação de texto.

A EA é uma ferramenta que pode e deve promover mudanças nas atitudes dos educandos. Por isso, desenvolvendo projetos interdisciplinares, a probabilidade de obter resultados positivos é maior.

As evidências obtidas a partir da análise dos dados do presente estudo sugerem que esforços para implantar o desenvolvimento sustentável devem ser somados aos investimentos em estudos para a implantação de projetos interdisciplinares com a temática ambiental nas escolas.

Assim, existe uma necessidade de se trabalhar intensamente com os docentes na perspectiva de sensibilizá-los para as questões interdisciplinares, bem como promover encontros pedagógicos visando o desenvolvimento de projetos.

\section{Agradecimentos}

À Secretaria Municipal de Educação do município de Garanhuns/PE e à Gerência Regional de Educação do Agreste Meridional pelo apoio e autorização. À Gerência Regional de Educação do Agreste Meridional e às direções das escolas estudadas por autorizarem a realização desta pesquisa. Aos gestores escolares pela colaboração. Aos professores das escolas estudadas, por terem compartilhado seus conhecimentos com os autores. Ao IFPE Campus Garanhuns pelo suporte para a realização da pesquisa. Ao IFPE pela concessão das bolsas de Iniciação Científica Técnica (PICTEC) e de Produtividade em Pesquisa (BPQ). 


\section{Referências}

AMBIVERO, M.C.; LOPES, A.F.; LOUREIRO, C.F.B. Industrialização e educação ambiental escolar: um estudo sobre práticas e expectativas de professores da rede municipal de ensino de Três Rios (RJ). Revista Brasileira de Educação Ambiental, v. 10, n. 1, p. 241-256, 2015.

BEZERRA, T.M.O.; GONÇALVES, A.A.C. Concepções de meio ambiente e educação. Revista Biotemas, v. 20, n. 3, p. 115-125, Florianópolis: UFSC, Set. de 2007.

BIZERRIL, M.X.A.; FARIA, D.S. Percepção de professores sobre a educação ambiental no ensino fundamental. Revista Brasileira de Estudos Pedagógicos, v. 82, n. 200/201/201, p. 57-69, Brasília, Jan/Dez, 2001.

BRASIL. Lei n. 9.795 de 27 de abril de 1999. Dispõe sobre a educação ambiental, institui a Política Nacional de Educação Ambiental e dá outras providências. Disponível em: $<$ http://portal.mec.gov.br/secad/arquivos/pdf/educacaoambiental/lei9795.pdf>. Acesso em: 18 Ago. 2014

CARNEIRO, S.M.M. Representações de educação ambiental e meio ambiente: diagnóstico na rede escolar pública de Paranaguá. Revista de Ciências Humanas, Especial Temática, p. 235-244, Florianópolis: EDUFSC, 2002.

CARVALHO, L.M. A Educação Ambiental e a formação de professores. Panorama da Educação Ambiental no Ensino Fundamental. Secretaria de Educação Fundamental, p. 55-63, Brasília: MEC/SEF, 2001.

CAVALCANTI NETO, A.L.G.; AMARAL, E.M.R. Análise de concepções e visões de professores de ciências sobre educação ambiental. Pesquisa em Educação Ambiental, v. 6, n. 2, p. 119-136, 2001.

CUBA, M.A. Educação ambiental nas escolas. ECCOM, v. 1, n. 2, p. 23-31, Jul./Dez. 2010.

ESTEVAM, C.S.; GAIA, M.C.M. Concepção ambiental na educação básica: subsídios para estratégias de Educação Ambiental. Acervo da Iniciação Científica, n. 2, p. 1-18, 2014.

FERNANDES, G.V.; MANSUR, C.B.; ALVES, M.A.M. O trabalho docente na escola estadual Ministro João Paulo dos Reis Veloso no município de Dourados, MS, em relação à Educação Ambiental. Anais do Encontro de Iniciação Científica - ENIC, n. 6, p. 1-12, 2014.

FORTES, C.C. Interdisciplinaridade: origem, conceito e valor. Disponível em: $<\quad$ http://www.pos.ajes.edu.br/arquivos/referencial 20120517101727.pdf>. Acesso em: 13 Nov. 2012.

GARCIA, J. O futuro das práticas de interdisciplinaridade na escola. Revista Diálogo Educacional, v. 12, n. 35, p. 211-232, 2012.

GATTÁS, M.L.B.; FUREGATO, A.R.F. A interdisciplinaridade na educação. Revista RENE, v. 8, n. 1, p. 85-91, Jan./Abr., 2007. 
GRUN, M. A outridade da natureza na educação ambiental. Reunião Anual da Associação. 2003. Disponível em: <http://www.ambiente.sp.gov.br/wpcontent/uploads/cea/Mauro Grun.pdf>. Acesso em: 05 Jan. 2012.

GUIMARÃES, Z.F.S.; SANTOS, W.L.P.; MACHADO, P.F.L.; BAPTISTA, J.A. Projetos de educação ambiental em escolas: a necessidade da sistematização para superar a informalidade e o improviso. Pesquisa em Educação Ambiental, v. 7, n. 1, p. 67-84, 2012.

INSTITUTO BRASILEIRO DE GEOGRAFIA E ESTATÍSTICA. Diretoria de Pesquisas, Coordenação de População e Indicadores Sociais. Cidades@infográficos. Disponível em: $<$ http://www.ibge.gov.br/cidadesat/painel/painel.php?codmun=260600\#topo > Acesso em 30 Set. 2012.

JACOBI, P. Educação e meio ambiente - transformando as práticas. Revista Brasileira de Educação Ambiental, n. 0, p. 28-35, Brasília: Rede Brasileira de Educação Ambiental, Nov. de 2004.

LEFF, E. Saber ambiental: sustentabilidade, racionalidade, complexidade, poder. 7. ed., Petrópolis/RJ: Vozes, 2009.

LIMA, V.F. Educação Ambiental: aspectos que dificultam o engajamento docente em escolas públicas do Distrito Federal. Dissertação de Mestrado. Programa de Pós-Graduação em Educação da Faculdade de Educação. Universidade de Brasília. 2012.

MACHADO, J.T. Um estudo diagnóstico da Educação Ambiental nas escolas do Ensino Fundamental do município de Piracicaba/SP. Anais do IV Encontro Nacional da Anppas. Brasília, Jun. 2008.

MARQUES, C.A. Estilos de pensamento de professores italianos sobre Química Verde na educação química escolar. Revista Electrônica de Enseñanza de lãs Ciencias, v. 11, n. 2, p. 316-340, 2012.

MEDINA, N.M. Formação de multiplicadores para a EA. Anais do I Seminário de Educação Ambiental, Salvador, 2002.

MENDES, F.L.S.; SOUZA, J.P.; NYLANDER, R.A. A concepção de Educação Ambiental entre docentes de duas escolas públicas do Ensino Fundamental de Belém (PA). Revista de Comunicação e Educação Ambiental, v. 2, n.1, p. 119, Jan./Jun., 2012.

NEHME, V.G.F.; COLESANTI, M.T.M. A pedagogia de projetos na práxis da Educação Ambiental: uma experiência na Escola Agrotécnica Federal de Uberlândia, MG, 2003-2004. Sociedade \& Natureza, Uberlândia, v. 17, n. 32, p. 133-145, Jun. 2005.

PEREIRA, A.P.T. A educação ambiental na escola municipal Maria Lúcia, Mamanguape-PB. Guarabira, 2012. Monografia de Graduação em Licenciatura Plena em Geografia. Universidade Estadual da Paraíba, 2012. 
PEREIRA, F.A., GUIMARÃES, F.M., SOUZA, A., ROCHA, M.B. Formação de professores em educação ambiental. Ciências em foco, v. 1, n. 3, p. 1-4, Ago. 2010.

REIGADA, C.; REIS, M.F.C.T. Educação ambiental para crianças no ambiente urbano: uma proposta de pesquisa-ação. Ciência \& Educação, v. 10, n. 2, p. 149-159, 2004.

REIS, M.F.C.T.; TALAMONI, J.L.B.; RUIZ, S.S.; NEVE, J.P.; TEIXEIRA, L.A.; CASSINI, L.F.; FESTOZO, M.B.; JANKE, N.; MAIA, J.S.S.; SANTOS, H.M.S.; CRUZ, L.G.; MUNHOZ, R.H. A educação ambiental na escola básica: diretrizes para a divulgação dos conhecimentos científicos. Pesquisa em Educação Ambiental, v. 7, n. 1, p. 29-48, 2012.

SANTOS, F.A.S.; PARDO, M.B.L. Concepções de professores sobre a educação ambiental: análise e perspectiva no município de Indiaroba, Sergipe. Revista Nordestina de Ecoturismo, v. 4, n. 1, p. 20-32, 2011.

SANTOS, V.M.N.; JACOBI, P.R. Formação de professores e cidadania: projetos escolares no estudo do ambiente. Educação e Pesquisa, São Paulo, v. 37, n. 2, p. 263-278, Mar./Ago. 2011.

SILVA, T.A.A. Educação ambiental no semiárido nordestino: apontamento de pesquisa e notas sobre prática educativa. Cadernos de estudos sociais, v. 27, n. 1, p. 181-192, Jan./Jun. 2012.

SLONSKI, G.T. Percepção ambiental dos professores dos cursos técnicos do IF-SC Campus Florianópolis - continente. Ambiente \& Educação, v. 16, n.1, p. 175-187, 2011.

SOARES, M.C.A.; GURGEL, B.S. Educação ambiental na escola. Disponível em:

$<$ http://bdm.bce.unb.br/bitstream/10483/4392/1/2012 MariadoCarmodosAnjosS oares.pdf $>$. Acesso em 16 Fev. 2014.

SORRENTINO, M.; TRAJBER, R.; MENDONÇA, P., FERRARO JR., L.A. Educação ambiental como política pública. Educação e Pesquisa, v. 31, n. 2, p. 285-299, São Paulo, Mai./Ago., 2005.

VIANA, P.A.M.O; OLIVEIRA, J.E. A inclusão do tema meio ambiente nos currículos escolares. Revista Eletrônica do Mestrado em Educação Ambiental, v.16, p. 1-17, Rio Grande, Jan.-Jun., 2006. 